\title{
LOCKE, LAS BESTIAS SALVAJES Y EL DERECHO A DESTRUIRLAS ${ }^{1}$
}

\author{
Olof Page \\ Pontificia Universidad Católica de Chile \\ opage@uc.cl
}

\begin{abstract}
Resumen
Creo que la defensa de John Locke del derecho a castigar está en tensión con su defensa de la igualdad humana. El propósito central de este artículo es mostrar que esta tensión podría ser resuelta si la justificación del derecho a castigar de Locke se basa en el concepto de confianza. Este concepto es claramente usado por Locke para justificar el derecho de resistencia. Pienso que también es posible usarlo para justificar la existencia del derecho a castigar. Pero, incluso si esta justificación fuera exitosa, algunos problemas permanecen.
\end{abstract}

Palabras Clave: Locke, derecho a castigar, igualdad, razón, confianza.

\section{Abstract}

I believe that John Locke's defense of the right to punish is in tension with his defense of human equality. The main purpose of this article is to show that this tension could be resolved if Locke's justification of the right to punish is based on the concept of trust. This concept is clarley employed by Locke to justify the right of resistance. I think that it is possible to use it also to justify the existence of the right to punish. But, even if this justification were succesful, some problems remain.

KEY WORDS: Locke, the right to punish, equality, reason, trust.

La relación entre el reino animal y la filosofía política tiene su historia o, mejor,
animales varias posibles historias. La que me interesa explorar aquí dice que los
no debiera ser: el espacio de la fuerza del deseo y del miedo. Según esta historia, el
orden político instaura entre los seres humanos un tipo de relación que los salvaría de

La idea central de este artículo fue presentada en las Cuartas Jornadas de Filosofía Moderna, con sede, esta vez, en la Universidad Alberto Hurtado. Agradezco los comentarios de los asistentes y, en especial, de Juan Ormeño, quien fue el encargado de comentar mi ponencia. 
la animalidad. Esa salvación se supone exitosa cuando el orden establecido es legítimo. Nosotros, animales humanos, tenemos interés en la legitimidad porque tenemos interés en dejar fuera de nosotros - es decir, fuera de la comunidad que podemos llegar a serla fuerza impredecible que cada uno podría eventualmente ejercer hacia los demás. Esto significa, entonces, que la posibilidad de que ingrese en la comunidad lo que la destruye no puede ser eliminada de manera definitiva, porque nosotros somos esa posibilidad. El hecho de que creamos que es, en algún sentido, justo que castiguemos a quien se comporta como si fuera un animal, es prueba de que somos conscientes de esa posibilidad.

John Locke creía que los ladrones, los criminales y -lo que parecía ser su mayor preocupación- los monarcas absolutos se comportan como si fueran bestias nocivas de las cuales tenemos el derecho a defendernos, en algunos casos simplemente eliminándolas. El comportamiento bestial justifica el castigo porque no es, según Locke, un comportamiento racional. El criterio que establece el límite entre lo bestial y lo humano -entre lo irracional y lo racional- es el respeto a ciertos principios morales que en Locke reciben el nombre genérico de ley natural. Si las bestias no son como nosotros porque no son racionales, entonces, si hay alguien que se comporta como una bestia, ese alguien se comporta como si no fuera uno de nosotros -como si no fuera un igual y, por tanto, debería ser tratado de esa manera. Pero Locke creía que los seres humanos debían tratarse unos a otros como iguales, ya que son, en un sentido moral, iguales. Es justamente por esta razón que cualquier poder que una persona ejerza sobre otra y que aspire a ser un poder legítimo, debe estar debidamente justificado, es decir, voluntariamente aceptado. Esa fue exactamente la tarea en la que se embarcó Locke en los Two Treatises of Government (1690).

Mi interés en las páginas que siguen es discutir la relación entre un par de importantes afirmaciones hechas por Locke, particularmente en el Second Treatise. La primera es la defensa de lo que podríamos llamar el principio de igualdad fundamental $y$, la segunda, la defensa del derecho a castigar. Como veremos, la justificación moral del derecho a castigar que Locke ofrece se basa, en parte, en la pérdida de derechos de la que el infractor de las normas de la ley natural sería objeto. La razón que amerita discutir este par de afirmaciones es que parece razonable, en una primera instancia, entender esa pérdida como una negación del principio de igualdad. Si el ser iguales desde el punto de vista moral implica, entre otras cosas, igualdad de derechos, podríamos pensar que pérdida de derechos implica pérdida de igualdad. Contribuye a esta interpretación el que, según Locke, la trasgresión de la ley natural es lo único que justifica el que, en el estado de naturaleza - es decir, en la convivencia humana sin gobierno legítimo- un hombre llegue "a tener poder sobre otro" (II, 8)2.

Ya que lo que nos interesa es la justificación moral del derecho a castigar en general, para nuestros fines es relativamente indiferente si el ejercicio de este derecho dice relación

2 Citaré ambos Treatises en el cuerpo del texto, señalando primero el tratado -si es el primero o el segundo- y luego el parágrafo. 
con el individuo en el estado de naturaleza -en ese caso, Locke habla de un "derecho natural ejecutivo"- o con el Estado ${ }^{3}$. Lo que es importante dejar en claro es que Locke cree que sí existe un derecho natural ejecutivo. Tampoco es directamente relevante que nos detengamos a examinar la plausibilidad moral de la ley de naturaleza ni la razón por la cual, según Locke, deberíamos obedecerla. Es suficiente entender la ley de naturaleza como un conjunto de principios o criterios o reglas morales, cuyo contenido es claro, preciso y objetivo -objetividad que está necesariamente condicionada a la existencia de Dios- y cuyo conocimiento está al alcance de todo aquél que lo busca (cf. II, 12).

La cuestión de la justificación del derecho a castigar constituye un elemento central en la filosofía política de Locke, al punto que forma parte esencial de su comprensión del poder político ${ }^{4}$. Reflexionar entorno al derecho a castigar contribuye a esclarecer el contenido y la coherencia de lo que para Locke es un criterio de pertenencia a la comunidad natural y política, i.e., el comportamiento según las normas de la recta razón. Quien puede ser legítimamente castigado es quien no se comporta según esas normas. Lo que me interesa hacer en las páginas que siguen es explorar una interpretación del vínculo entre racionalidad y ley natural basado en la noción de confianza. La idea central es que, quien quebranta la ley natural, no se guía por las normas de la recta razón, pues su accionar introduce en la comunidad desconfianza y esa desconfianza es colectivamente perjudicial. La razón por la cual me interesa explorar esta idea es que, como veremos, ésta podría tener la ventaja de no atentar contra el principio de igualdad. Creo que es relevante explorar esta posibilidad porque, de resultar factible, una de las contribuciones más significativas de Locke al pensamiento político moderno y, particularmente, a la tradición liberal - una interpretación específica del principio de igualdad expresada en la igual posesión de ciertos derechos específicos- no sería, a fin de cuentas, una contribución fallida. Además, cuestiones como el derecho a castigar resultan especialmente interesantes, pues a menudo ponen a prueba los límites que le dan forma a las relaciones políticas entre los ciudadanos y el poder político; límites que, en el caso de Locke, están demarcados por este principio de igualdad que el derecho a castigar parece amenazar. Sin embargo, aunque esta exploración resulte plausible, en la sección final de este ensayo haré referencia a un punto que me parece que, en

3 Para una discusión sobre las dificultades que encierra en Locke la existencia de un derecho natural ejecutivo, véase Simmons (1992: 134-40).

4 "Considero, pues, que el poder político es el derecho de dictar leyes bajo pena de muerte $\mathrm{y}$, en consecuencia, de dictar también otras bajo penas menos graves, a fin de regular y preservar la propiedad y ampliar la fuerza de la comunidad en la ejecución de dichas leyes y en la defensa del Estado frente a injurias extranjeras. Y todo ello con la única intención de lograr el bien público" (II, 3). 
un nivel distinto y, quizás, menor, sigue haciendo del derecho a castigar una cuestión problemática.

En general, los estudios sobre la confianza en Locke se concentran en la importancia de este concepto a la hora de explicar parte del contenido del acto mediante el cual la sociedad civil delega el poder a un representante. Me parece que la confianza también podría ser usada como una manera de mostrar qué es lo que Locke quiere decir cuando se refiere a quienes quebrantan la ley natural como bestias salvajes o criaturas nocivas, es decir, como seres que no actúan según las normas de la recta razón. La cuestión es problemática porque Locke no puede estar diciendo con esto que quienes quebrantan la ley natural no se guían por las normas de la recta razón debido a que se equivocan en identificar los medios adecuados para alcanzar un determinado fin. Quien quebranta la ley natural ciertamente no deja de guiarse por las normas de la recta razón en ese sentido. Tampoco podría estar diciendo que el trasgresor no es racional porque el acto que realiza le trae a él malas consecuencias. En más de alguna ocasión, quebrantar la ley natural puede ser personalmente ventajoso. Esto hace necesario entonces encontrar un modo de entender lo que significa comportarse según las normas de la recta razón que no descanse en estas interpretaciones.

El otro punto que hace problemática la relación entre el principio de igualdad y el derecho a castigar es que Locke parece justificar su principio de igualdad apelando, no ya a una cierto concepto - al parecer, poco claro- de razón, sino que a la idea de criatura racional. Si, quien quebranta la ley natural, no se comporta según las normas de la recta razón, podríamos pensar que Locke está sosteniendo que, quien quebranta la ley natural, no es un igual porque no es una criatura racional. Las pocas ocasiones en las que algunos estudiosos han abordado estas cuestiones problemáticas ha sido para terminar concluyendo que, o bien Locke no es claro en esta materia (Simmons 1992: 139-40), o bien el argumento de la racionalidad es poco convincente (ibíd., 153), o bien su concepción del trasgresor como una bestia nociva es un gran problema para su principio de igualdad (Waldron 2002: 143).

Si la interpretación que me interesa explorar resulta plausible -i.e., vincular la idea de razón (o de comportamiento según las normas de la recta razón) con la idea de confianza-, podría ser más fácil conciliar la posición de Locke con respecto a la relación entre el derecho a castigar y su compromiso con el principio de la igualdad fundamental, pues atentar contra los vínculos de confianza -es decir, trasgredir la ley natural- no implicaría necesariamente una exclusión de la comunidad humana basada en la noción de criatura racional, en tanto dicha noción es usada como aquello que nos hace moralmente iguales, sino más bien en la idea de una criatura racional que no se comporta según la normas de la recta razón -donde comportarse según las normas de la recta razón equivale a comportarse según aquellas normas que favorecen la confianza $y$, por tanto, la seguridad mutua, entre otras $\cos ^{5}$. Como veremos, viene a reforzar

5 No estoy diciendo con esto que la seguridad mutua sea lo único que interesa, pero claramente para Locke éste es uno de los propósitos centrales de la existencia de la sociedad política. 
esta hipótesis la idea de la proporcionalidad del castigo (cf. II, 8). Si la "bestialización" del trasgresor implicase algo así como la exclusión definitiva de la comunidad humana -i. e., la pérdida de su estatus moral-, la cuestión de la proporcionalidad del castigo no tendría ninguna relevancia moral para Locke. Esta última es, en suma, una razón para favorecer una interpretación específica de la analogía entre el trasgresor y la bestia nociva que pretende hacer compatibles el principio de igualdad con el derecho a castigar. Me parece oportuno notar, además, que el problema que nos ocupa aquí es un asunto que también se presenta como problemático en la discusión contemporánea acerca de la justificación del castigo. Cualquier teoría moral que tome en serio tanto el castigo como los derechos, se encontrará con la dificultad de explicar por qué ciertos tratos a los que son sometidas las personas cuando son castigadas nos parecen legítimos en circunstancias que, esos mismos tratos en otro contexto, nos parecería que atentan contra los derechos de esas mismas personas. El asunto consiste entonces en mostrar por qué la aplicación del derecho a castigar no implica la violación de ciertos derechos ${ }^{6}$. El caso de Locke es una manera - problemática, por cierto- de abordar la cuestión.

Tomemos una de las descripciones que Locke ofrece del principio de igualdad: "habiendo sido todos los hombres dotados con las mismas facultades, y al participar todos de una naturaleza común, no puede suponerse que haya entre nosotros una subordinación que nos dé derecho a destruir al prójimo como si éste hubiese sido creado para nuestro uso, igual que ocurre con esas criaturas que son inferiores a nosotros" (II, 6). Esta manera de afirmar la igualdad moral entre las personas parece entrar en tensión con el derecho a castigar, pues, según Locke, sí existiría una instancia en la cual tendríamos el derecho a destruir a otro. Quien quebranta la ley natural se convierte en una amenaza contra toda la humanidad y, "por las mismas razones por las que [se] puede matar a un lobo o a un león" (II, 16) se le puede matar a él, toda vez que se crea que el agresor constituye una amenaza para mi propia conservación o para la conservación de la humanidad. A quienes quebrantan la ley natural se les considera como una "criatura nociva" (II, 10) porque "no se guían por las normas de la ley común de la razón, y no tienen más regla que la de la fuerza y la violencia. Y, por consiguiente, pueden ser tratados como bestias de presa: esas criaturas peligrosas y dañinas que destruyen a todo aquel que cae en su poder" (II, 16) ${ }^{7}$. Este es un caso evidente en el que el derecho a castigar se

6 Para una interesante reflexión sobre este punto véase el ya clásico artículo de Quinn (1985: 328-9).

7 Desde luego esta última afirmación no implica que, quienes puedan ser tratados como bestias de presa puedan ser tratados así porque han sido creados para nuestro uso. El derecho a destruir al prójimo -o, mejor, el derecho a castigarlo proporcionalmente- existe únicamente porque éste quebranta la ley natural y eso tiene importantes consecuencias morales. 
justifica mediante la pérdida total de derechos por parte del trasgresor. Pero no siempre la pérdida tiene esa amplitud. La idea es que la pérdida de derechos sea proporcional a la trasgresión cometida. No toda trasgresión implica el derecho a destruir al trasgresor (cuando por destrucción se entiende destrucción total). Por esta razón, también se podría afirmar que bestia nociva no es solo quien representa una clara amenaza de muerte, sino todo aquél que quebranta la ley natural, pues ese quebrantamiento muestra que el trasgresor no se guía por la ley común de la razón y que tiene por regla la fuerza y la violencia, independientemente de que dicho quebrantamiento constituya o no una amenaza de muerte ${ }^{8}$.

No hay que olvidar en relación con este punto, además, que la figura por la que Locke muestra especial interés cuando discute estas cuestiones -es decir, cuando habla de ladrón o criminal o trasgresor de la ley natural- es la del monarca absoluto, cuya sola existencia instaura un estado de guerra entre quien gobierna y los gobernados, y es, por lo mismo, incompatible con la sociedad civil (II, 90). Tanto es así que, bajo una monarquía absoluta, los súbditos deberían llamarse, según Locke, más bien esclavos (II, 91). Consideraciones similares se aplican a quienes, habiendo contado con la confianza del pueblo para convertirse en su representante, no han ejercido el encargo que se les encomendó según el fin para el cual fueron elegidos -el bien público- y se extralimitaron en el ejercicio del poder. Este rompimiento de la confianza quita de inmediato legitimidad a quienes gobiernan y justifica la resistencia civil (II, 226-243). Me parece que estas observaciones van en apoyo de la hipótesis que desarrollo aquí ya que creo plausible extender la razón que justifica la resistencia civil -el rompimiento de la confianza- a la justificación del derecho a castigar. De hecho si se afirma, por ejemplo, que la justificación del derecho natural ejecutivo es "the whole point of the Second Treatise" (Ashcraft 1986: 332) porque es dicha justificación la que, en último término, legitima la resistencia del pueblo al rey, deberíamos decir más bien que son justamente las razones que justifican el derecho natural a castigar las que deberían ser extendidas a la justificación del derecho a la resistencia civil. Por este motivo, si es

8 En el Segundo Tratado las alusiones a la pérdida de derechos se dan mayoritariamente en relación con actos que merecen la muerte, es decir, pérdida total de derechos (II, 23, 172). En el Primer Tratado, Locke se refiere a casos menos dramáticos, casos en los cuales, por ejemplo, un padre pierde los derechos sobre su hijo (I, 100). De todas formas, la posición de Locke en este punto parece ser bastante insensible a los niveles de trasgresión, pues, según él, por una cuestión de prevención, es perfectamente "legal” matar a un ladrón que no ha manifestado intención de arrebatar mi vida, "pues cuando alguien hace uso de la fuerza para tenerme bajo su poder, ese alguien, diga lo que diga, no logrará convencerme de que una vez que me ha quitado la libertad, no me quitará también todo lo demás cuando me tenga en su poder" (II, 18). Lo que el ladrón ha hecho con su comportamiento es introducir -en la terminología de Locke- un estado de guerra entre él y su víctima y, en tales condiciones, matarlo es un derecho que se deriva del derecho a la auto-preservación (II, 19). Me parece, en todo caso, que deberíamos considerar las afirmaciones de Locke sobre la prevención simplemente como una manera, entre otras, de interpretar la pérdida de derechos. Lo que no está en cuestión es que esa pérdida existe y que debe ser proporcional. 
que la justificación del derecho natural ejecutivo no resulta plausible, la justificación de la resistencia civil tampoco (Simmons 1992: 127). Como lo señalaba al comienzo del artículo, no es necesario para nuestros propósitos que nos detengamos a analizar o defender la existencia de un derecho ejecutivo natural. Lo que me interesa destacar es que, si la justificación de la resistencia civil depende de la justificación del derecho ejecutivo natural, entonces parece razonable pensar que las razones que justifican a éste último son también las que justifican al primero: la pérdida de confianza ${ }^{9}$. Hasta donde tengo noticia, entre quienes se han dedicado al estudio del derecho a castigar en Locke no figura la pérdida de confianza como una manera de justificar dicho derecho ${ }^{10}$.

Antes de proseguir con el argumento me parece necesario decir algunas pocas palabras sobre el estado de naturaleza y la ley de naturaleza en Locke. Debemos tener presente que, a diferencia de lo que ocurre, por ejemplo, con Hobbes, el estado de naturaleza en Locke no es un estado de inevitable conflicto en el que exista, además, un completo vacío normativo. Esto significa que el estado de naturaleza no es equivalente al estado de guerra (II, 19). Es posible que existan individuos que vivan de acuerdo a los deberes que, según Locke, claramente establece la ley natural (II, 12) y que, a pesar de uno que otro inconveniente, no necesiten del gobierno para solucionar sus posibles controversias. Por este motivo es que deberíamos decir que la libertad de la que gozan los individuos en el estado de naturaleza no es libertinaje (II, 6). Esto significa que, a pesar de que no exista poder político alguno de carácter estatal, hay cosas que los individuos deben y no deben hacerse unos a otros -cuestión esta última ciertamente impensable para Hobbes. El problema es que, por diversas razones, no todos ven esto con claridad (II, 124) y se generan, como consecuencia, inconvenientes que hacen preferible realizar un acuerdo que tenga por fin establecer un juez común para proteger eso que puede verse amenazado en el estado de naturaleza: la vida, las posesiones, la libertad y la salud (II, 123). Entre los deberes fundamentales que establece la ley natural están el deber de preservarse a sí mismo y el deber de preservar al resto de la humanidad (II, 6). A pesar de su relevante conexión con el derecho a castigar, no me detendré a examinar si estos deberes están o no debidamente justificados.

Parece ser relativamente claro en qué sentido el derecho a castigar podría entrar en conflicto con el principio de la igualdad fundamental. Si es que todos somos iguales ¿por qué uno de nosotros podría ser objeto de violencia legítima? ¿Qué es lo que hace

9 No quiero decir con esto que las razones sean exactamente las mismas, sino que en ambos casos parece razonable entender que es la pérdida de confianza lo que justifica moralmente un cierto tipo de reacción.

10 De hecho, en los cuatro volúmenes de los Critical Assesments dedicados a Locke no se encuentra ningún artículo que trate ni siquiera la cuestión del derecho a castigar de manera explícita. 
que, quien quebranta la ley natural, deje de pertenecer -en un sentido que hay que especificar- a esa comunidad (cf. II, 128) de la que forman parte los seres humanos que reconocen (o que tienen la capacidad de reconocer) en la ley natural un conjunto de normas morales claras e inteligibles (cf. II, 124)? La respuesta de Locke se mueve en dos registros; uno de carácter teológico: así como Dios es fundamento último de la existencia de ciertos derechos, Él mismo los puede eliminar cuando la ley natural no es respetada ${ }^{11}$; y otro de carácter secular: ya que el actuar mal evidencia un comportamiento que no se basa en las reglas de la recta razón, dicho actuar envuelve una pérdida total o parcial de los derechos que posee la criatura racional (cf. II, 171, $181)^{12}$. Es este segundo registro el que me interesa indagar porque, entre otras cosas, no parece en absoluto evidente que la pérdida de derechos sea una consecuencia moral obvia de la trasgresión de la ley natural, es decir, habría que explicar por qué la violación de los derechos de otro causa la pérdida de derechos de parte de quien cometió la violación ${ }^{13}$.

Es importante notar que la distinción entre un registro teológico y otro secular en Locke debe ser tomada con mucha cautela. En último término es perfectamente argumentable que parte significativa de la teoría política de Locke se basa en, por lo menos, una premisa de carácter teológico ${ }^{14}$. No me parece que sea necesario que tomemos aquí posición respecto de esta cuestión, es decir, no creo necesario intentar responder a la pregunta sobre qué está vivo y qué está muerto -para usar una expresión de John Dunn- en el pensamiento político de Locke (donde lo que está muerto tendría que ver con las premisas teológicas y lo que está vivo, con argumentos cuya posible verdad no dependa de creencias religiosas) ${ }^{15}$. Como veremos en lo que sigue, la defensa del principio de igualdad se basa justamente en, por lo menos, una premisa de carácter teológico y eso no es enteramente relevante para nuestros propósitos.

Con el fin de explorar la posibilidad de que la justificación de la pérdida de derechos no implique dejar de considerar al trasgresor como un igual, expondré primero las bases del principio de igualdad en Locke-i.e., eso que justifica que nos consideremos,

11 La relación entre Dios y la pérdida de derechos está basada en la idea de Dios como creador y propietario de la creación. Cf. II, 6.

12 Sobre la presencia de esto dos registros en Locke, véase Simmons (1992: 153-4).

13 En la discusión contemporánea este punto es tocado con claridad por Quinn (1985).

14 Según Dunn, el asunto es mucho más serio, pues existe "the innate dependence of an extremely high proportion of Locke's arguments for their very intelligibility, let alone plausibility, on a series of theological commitments" (1982: xi).

15 De hecho, ni siquiera estoy seguro de que esta sea una buena manera de poner las cosas. 
desde el punto de vista moral, como iguales- para mostrar luego que la justificación del derecho a castigar no es incompatible con este principio así entendido. Ya que el propósito de este ensayo no es discutir la plausibilidad del principio de igualdad en sí mismo, adoptaré la interesante interpretación que Jeremy Waldron (2002) ofrece de las bases de la igualdad en Locke. Las razones que explican esta adopción son dos: primero, Waldron aborda un tema -i.e., las bases de la igualdad en Locke- que, pese a su evidente importancia, no ha sido tratado con la debida profundidad -o, para ser más precisos, simplemente no ha sido tratado-y, segundo, su tratamiento del punto me parece convincente. De todas formas, parte importante de lo que diré en relación con el derecho a castigar no depende directamente de si la interpretación de Waldron (u otra) respecto de las bases de la igualdad es efectivamente convincente. Lo único que se necesita para comprobar la plausibilidad de nuestra exploración es que la interpretación del concepto de razón (o de normas de razón) que figura en la justificación de la pérdida de derechos, no incluya elementos que necesariamente deberían estar presentes en el concepto de razón cuando éste es usado como parte del contenido de las bases de la igualdad al afirmar, por ejemplo, que los seres humanos son moralmente iguales porque son racionales. En este sentido, podría bastar especificar el concepto de razón en la justificación de la pérdida de derechos y limitarse a mostrar luego que ese concepto así entendido no es parte de la idea de racionalidad como base de la igualdad, sin ni siquiera señalar que otros elementos forman parte de dicha base. Esto es lo que significa que parte importante de lo que diré en relación con el derecho a castigar no depende directamente de una interpretación específica del principio de igualdad. Expondré la interpretación de Waldron simplemente para mostrar en qué sentido esto es así.

Según Waldron, el criterio que justifica en Locke el que nos consideremos como iguales -es decir, el criterio que justifica el contenido del principio de igualdad establecido en, por ejemplo, II, 6- es la capacidad racional, entendida como el poder de abstraer, es decir, el poder de razonar en base a ideas generales (2002: 73-4). Esto es algo que Locke afirma en el Essay Concerning Human Understanding, (1689: 2.11.9-11). Es esta capacidad la que le permitiría a los seres racionales, entre otras cosas, reconocer la existencia de Dios y relacionar su idea con la existencia de una ley moral. Este es el criterio que, según Locke, haría posible distinguir a los seres racionales de los brutos.

Podríamos pensar que el hecho de la desigual posesión de esta capacidad de abstracción debería tener consecuencias sobre el principio de igualdad, de manera que, quien tiene menos capacidad de abstracción no es igual, desde el punto de vista moral, a quien tiene más. Pero la idea aquí es que esta capacidad debería entenderse como una propiedad de rango (range property) (Waldron 2002: 76-7), es decir, como una propiedad cuya sola posesión, independientemente del lugar que pueda ocuparse en la escala de ese rango, permite calificar a un individuo como racional y, por tanto, como un igual entre seres racionales. Este sería el umbral o la línea de suficiencia que Locke establece para considerar la racionalidad como un criterio-base para la igualdad. Tener esta capacidad en su grado mínimo es suficiente, pues con ella los seres racionales tienen "luz suficiente para conducirlos al conocimiento de su Hacedor, y para mostrarles cuáles son sus deberes" (1689: 1.1.5). Quienes tienen esa capacidad deben tratarse unos a otros como iguales porque, como ellos mismos están en condiciones 
de reconocerlo racionalmente, han sido enviados a este mundo por orden de Dios y "para cumplir su encargo", siendo todos ellos "propiedad de quien los ha hecho, y han sido destinados a durar mientras a Él le plazca, y no a otro" (II, 6) ${ }^{16}$. El no considerar a otro como un igual implicaría considerarlo como un medio para satisfacer intereses personales $\mathrm{y}$, por tanto, considerarlo como si fuera de su propiedad o, al menos, como si no fuera propiedad de Dios.

Un punto evidentemente problemático es la relación entre la posesión de una cierta propiedad -la capacidad de abstracción- y el hecho de que de esa propiedad se derive una premisa de carácter normativo. Esto podría significar que Locke está cometiendo la tan famosa falacia naturalista, es decir, derivando un "deber ser" de un "es". No discutiré sobre este punto, pues, como ya lo he dicho, mi propósito no es analizar el principio de igualdad en sí mismo, sino que examinar si la justificación que Locke ofrece del castigo amenaza o no la existencia del principio de igualdad, cuya plausibilidad simplemente supondré (o, más bien, remito para su defensa al argumento de Waldron recién bosquejado). Además, Waldron (2002: 68-9) defiende a Locke de la acusación relativa a la falacia naturalista. No me detendré a considerar si dicha defensa es o no exitosa $^{17}$. Para nuestros fines es suficiente tener claro lo siguiente. Locke defiende un

16 Por supuesto, es esta premisa teológica la que muestra la relevancia de la propiedad seleccionada. Sin esta premisa, la propiedad seleccionada no se justifica por sí misma o, más precisamente, el umbral establecido se vuelve completamente arbitrario.

17 Un segundo punto problemático que no trataré dice relación con un aspecto del contenido del principio de igualdad. Hemos visto que parte importante de dicho contenido se basa en la idea de naturaleza común: "habiendo sido todos los hombres dotados con las mismas facultades, y al participar todos de una naturaleza común, no puede suponerse que haya entre nosotros una subordinación que nos dé derecho a destruir al prójimo como si éste hubiese sido creado para nuestro uso, igual que ocurre con esas criaturas que son inferiores a nosotros" (II, 6). Una variante de lo mismo puede observarse también en la siguiente formulación: "Nada hay más evidente que el que criaturas de la misma especie y rango, nacidas todas ellas para disfrutar en conjunto de las mismas ventajas naturales y para hacer uso de las mismas facultades, hayan de ser también iguales entre sí, sin subordinación o sujeción de unas a otras (...)" (II, 4). El problema con la referencia a una naturaleza común o a una especie es que en el Essay Locke manifiesta claramente su escepticismo con respecto a la existencia de especies: "The Species of Things to us are nothing but the ranking them under distinct Names, according to the complex Ideas in us" (3.6.8). Considerando que, según Locke, es un hecho que los seres humanos tienen diferentes habilidades y características (II, 54), el escepticismo sobre las especies parece negar a Locke lo que su principio de igualdad necesita: un criterio que le permita afirmar que, pese a esas diferencias, los seres humanos "participan" (II, 54) de la igualdad en lo que respecta a la jurisdicción o dominio de uno sobre otro. Para nuestros fines basta afirmar que la identificación de una capacidad entendida como una propiedad de rango puede funcionar como ese criterio que se necesita en la medida en que lo relevante ahora no es la pertenencia a una especie, sino tener las características que, dentro de un cierto rango, hacen que un determinado individuo pueda ser considerado racional. Como lo señala Waldron, desde esta perspectiva, el dominio de la igualdad debe dejar de ser el dominio de la pertenencia a una especie para convertirse en 
principio de igualdad cuyas bases dicen relación con una semejanza relevante cual es la capacidad de abstracción y lo que ésta permite: el reconocimiento de la ley natural o moral. Dicha capacidad funciona como una propiedad de rango, es decir, como una propiedad cuya sola posesión cumple la función deseada, independientemente del nivel en el que se la posea. Esto le permite a Locke afirmar que las diferencias que de hecho existen en la posesión de esa propiedad no son moralmente relevantes.

Hasta el momento hemos visto que Locke defiende un cierto principio de igualdad, que defiende también un derecho a castigar y que ese derecho se basa en la pérdida de derechos por parte del trasgresor. Hemos hecho notar que esa pérdida de derechos parece entrar en tensión con el principio de igualdad y hemos, hasta el momento, simplemente sugerido una manera de evitar esa tensión, vinculando racionalidad y confianza. Ahora es necesario desarrollar más específicamente esa sugerencia y mostrar por qué la pérdida de derechos como consecuencia de la trasgresión de la ley natural no atentaría contra el principio de igualdad.

Lo primero que me parece importante apuntar es que la confianza no es lo que nos define como iguales, sino que es algo que se da entre iguales. De manera que pérdida de confianza no significa pérdida de igualdad. La necesidad de argumentar en esta dirección es algo que una defensa lockeana de la compatibilidad entre el principio de igualdad y el derecho a castigar demanda. Como lo señalábamos al comienzo, no podría entenderse de otra forma la relevancia que tiene para Locke la cuestión de la proporcionalidad del castigo. Si las personas perdieran su condición de iguales cuando quebrantan la ley natural porque no se están comportando como seres racionales -en el sentido de racionalidad como propiedad de rango-, la aplicación proporcional del castigo no sería una demanda de justicia. Esto significa, además, que a Locke no le preocuparía -como de hecho le preocupa- que el castigo cumpla con dos propósitos fundamentales: la reparación y la disuasión (II, 8) ${ }^{18}$.

el dominio de la semejanza relevante (Waldron 2002: 67). Esto significa, entre otras cosas, que quienes son considerados racionales en virtud de la semejanza relevante no tienen que corresponder necesariamente a lo que, en sentido taxonómico, llamamos "hombre" (cf. Essay 2.11.11). Este es un punto muy relevante, pues lo que está en juego es una defensa explícita de la relación entre el Locke del Essay y el de los Treatises, con el fin de mostrar que el escepticismo respecto de las especies tiene consecuencias morales y políticas que el propio Locke estaría en condiciones de manejar. La propuesta de Waldron me parece convincente y relevante, más aún, si consideramos que es muy poco (o casi nada) lo que se ha trabajado en esa línea. De todas formas, no ahondaré en este importante problema.

18 A pesar de que no tenemos espacio aquí para discutir en detalle la relación entre el derecho a castigar y sus dos propósitos fundamentales, es importante enfatizar una vez más que 
Lo que es necesario mostrar entonces es que cuando Locke se refiere a los trasgresores como no actuando según las normas de la recta razón y, por tanto, como actuando en un cierto sentido irracionalmente, la idea de razón en juego ahí no es la que Locke usa para justificar las bases de su principio de igualdad. Si lo fuera, entonces quienes quebrantan la ley natural podrían ser tratados exactamente igual a como trataríamos a una bestia nociva, sin preocupación alguna por la proporcionalidad de nuestra reacción. La proporcionalidad del castigo es moralmente relevante porque, quien ha quebrantado la ley natural y con ello ha ejercido un poder arbitrario sobre los demás, sigue teniendo esa propiedad que lo hace un igual. De lo contrario, tendríamos que suponer algo un poco extravagante: quien hace un momento, porque era un sujeto racional, estaba sometido a la ley natural y era poseedor de los derechos que ella define, ha dejado de serlo porque, en virtud del acto cometido, su condición de criatura racional desapareció. Si esto fuera así, entonces el trasgresor no podría ser justamente castigado, pues, al no ser ya racional, no está más sujeto a la ley natural de lo que lo están las piedras y los pájaros, por ejemplo.

Como lo señalaba, la posibilidad que me interesa considerar supone ver la confianza como un elemento central a la hora de explicar la existencia de la sociedad civil en Locke. Si bien el término "confianza" no figura explícitamente con este propósito, una serie de afirmaciones de Locke relativas a lo que sucede cuando alguien trasgrede la ley natural y a lo que significa hablar de unión en relación con la sociedad, permiten interpretar las cosas de esta manera. Veamos. Quien trasgrede la ley natural lo que hace, según Locke, es romper ciertas "ataduras" que "impedían a los hombres herirse y hacerse violencia unos a otros" (II, 8). Además, el rompimiento de esas ataduras constituye una "trasgresión contra toda la especie" (II, 8). Creo plausible interpretar este efecto -el rompimiento de ciertas ataduras- como pérdida de confianza, pues las ataduras a las que Locke hace referencia en el pasaje recién citado son principios morales (i.e., leyes naturales) cuya función es garantizar paz y seguridad (cf. II, 8). Parece razonable entender que la eficacia normativa de dichos principios depende, en último término, de la confianza y que, por tanto, no es el producto exclusivo de la fuerza coercitiva del Estado. De esta manera, lo que podría explicar la efectiva y constante existencia de paz y seguridad es la confianza, confianza en que los demás -nuestros pares en la sociedad civil- reconocen en la ley natural un conjunto de normas morales

es la regla de proporcionalidad la que funciona como criterio para delimitar la correcta aplicación del castigo y que, por tanto, no debe haber mayor reparación que la debida ni se debe castigar más al trasgresor simplemente para hacer más efectiva la disuasión. Esto significa que la reparación es el resultado de la aplicación proporcional del castigo y que la disuasión está estrechamente vinculada a dicha aplicación. Un abandono de la proporcionalidad con el fin de disuadir más eficientemente implica, para Locke, violar la ley de naturaleza y es más importante respetar la ley de naturaleza que disuadir más eficientemente, en el supuesto -bastante discutible- de que exista una clara relación entre castigar más y disuadir más. Agradezco a Juan Ormeño el haber hecho una observación que me permitió explicitar este punto. 
efectivamente vinculantes. Desde luego, si tuviéramos la certeza de que los demás conocen la ley natural, la entienden como efectivamente vinculante y se comportan de acuerdo con esa creencia, no sería necesaria la presencia del Estado. En virtud de lo dicho anteriormente (sección III), sabemos que eso no es completamente así. Ayuda a complementar esta idea - la idea de que la confianza es condición de posibilidad de la eficacia de ciertas normas y reglas- el recordar que el estado de naturaleza en Locke puede adquirir formas bastante sofisticadas, caracterizadas por la existencia de moneda, propiedad de tierra, comercio y otras. Resulta difícil pensar que este tipo de relaciones serían factibles sin que de por medio estuviera, entre otras cosas, la confianza.

Por otra parte, los efectos socialmente corrosivos que genera la pérdida de confianza tienen la ventaja de permitirnos entender por qué Locke cree que la trasgresión de la ley natural es contra toda la especie y no solamente contra la víctima de la trasgresión.

Estas observaciones también enfatizan, creo, el vínculo entre razón y confianza -y, por tanto, entre irracionalidad y pérdida de derechos- pues la razón es, según Locke, "el lazo común mediante el cual el género humano se une en camaradería y sociedad" (II, 172). Parece razonable pensar que sin confianza no existe camaradería, pues, de quien trasgrede la ley natural y se comporta, por tanto, como una bestia salvaje, no se “puede esperar seguridad" (II, 172). Esto muestra, además, que Locke está usando el concepto de razón de manera más amplia que como la mera capacidad para establecer una adecuada relación entre medios y fin, vinculándolo directamente con la camaradería y la sociedad. Por último, el papel fundamental de la confianza como elemento de cohesión social lo expresa Locke en el ensayo VIII de los Essays on the Law of Nature, al referirse a ella -usando explícitamente el término "trust"- como "the bond of society" (132). Por esta razón, además, es posible afirmar que, quien quebranta la ley natural, puede ser visto como alguien que no cumple con el pacto que hizo posible la formación de la sociedad, y el cumplimiento de los pactos es, según Locke, uno de los factores en los cuales descansa la sociedad humana (ibíd. 87).

Creo que estas citas muestran por qué parece plausible pensar que la confianza en Locke no es solo parte del acto de delegación de poder de la sociedad a el o los gobernantes, sino que constituye también un criterio mediante el cual se pueden explicar las consecuencias morales del quebrantamiento de la ley natural en general, se den éstas en el estado de naturaleza o en la sociedad civil. Comportarse según las normas de la recta razón, es decir, comportarse racionalmente, quiere decir aquí actuar según aquellas normas que nos permiten vivir en paz, y la confianza es un instrumento indispensable para conseguir ese objetivo ${ }^{19}$.

19 Aunque se mueve en otro nivel, es interesante destacar en la discusión la posibilidad de considerar la demanda de racionalidad como una demanda de coherencia. Es posible decir que, quien rompe los lazos de confianza, no actúa racionalmente porque no se comporta conforme a aquellas creencias que lo llevaron a unirse en sociedad con otros; fundamentalmente, la creencia de que los demás son personas libres e iguales. Al quebrantar la ley natural, el trasgresor se comporta como si los afectados por esa trasgresión no fueran libres e 
Debemos, por último, tener presente en esta discusión una cuestión bastante elemental: lo que saca a los hombres del estado de naturaleza, es decir, lo que "crea una comunidad" (II, 211) es un "acuerdo que cada individuo hace con los demás" (II, 211). Considerando la naturaleza evidentemente no-institucional de este acuerdo -es decir, considerando que es un acuerdo que constituye aquello que hará posible luego la existencia del gobierno y sus instituciones- parece plausible afirmar que dicho acuerdo no tiene otro sustento que la confianza ${ }^{20}$.

Me parece también que calificar la trasgresión de la ley natural como un comportamiento irracional -cuando se tiene como norma de razón las normas de la

iguales, disponiendo de su propiedad, vida, salud e integridad física, como medios para satisfacer sus propios intereses. Esto no es racional, porque implica que el trasgresor trata a las personas de manera contradictoria respecto de lo que él cree que son, i.e., personas libres e iguales. Resulta plausible asumir que el trasgresor cree que las personas son libres e iguales pues estamos suponiendo que la sociedad en la que vive es producto del acuerdo (tácito o explícito) entre las partes y que dicho acuerdo está basado en la convicción de que las personas no están naturalmente subordinadas unas a otras - es justamente por esa razón que solo el acuerdo voluntario legitima la existencia del poder político. Esta es la explicación -convincente a mi juicio-que ofrece Simmons (1992: 42).

20 Simmons (1992: 152-4) considera que la justificación de Locke de la pérdida de derechos basada en la racionalidad -i.e., el trasgresor no es racional y la racionalidad es un requisito para estar sujeto a los derechos que la ley natural establece- no resulta plausible, pues quebrantar la ley natural no es una condición ni necesaria ni suficiente de falta de racionalidad. En un intento por ofrecer una justificación lockeana que no tenga estos defectos, Simmons propone la idea de reciprocidad para dar cuenta de la pérdida de derechos. La idea central es que la existencia de un sistema de reglas (leyes, convenciones) justo depende de la restricción de la libertad de todas las personas que han decidido someterse a dichas reglas. Por esta razón, cualquier derecho que las reglas puedan establecer debería ser garantizado solo a quienes las obedecen (Simmons 1992: 153). A esto es a lo que podemos llamar el principio de reciprocidad. Cuando uno de los sujetos que obtiene beneficios de la existencia de dichas reglas atenta contra los derechos de otro, se está beneficiando injustamente de la existencia del sistema de reglas pues está obteniendo beneficios sin restringir su libertad. Por esta razón, el individuo en cuestión debería perder derechos y ser, en consecuencia, proporcionalmente castigado. Se podría quizás sostener que la reciprocidad así entendida es equivalente -en lo que a su función argumentativa se refiere- a la confianza y que, entonces, lo que yo estaría haciendo en este ensayo es simplemente usar otra palabra para hablar de lo mismo que habla Simmons. La verdad es que no tengo problema con entender reciprocidad y confianza como equivalentes y no creo que dicha equivalencia haga inútil el argumento de este ensayo. La razón es la siguiente. Simmons rechaza la racionalidad como justificación de la pérdida de derechos y, en su lugar, plantea el principio de reciprocidad. $\mathrm{Mi}$ intención, en cambio, es vincular la racionalidad con la confianza para justificar la pérdida de derechos. Creo que la interpretación que hace Simmons del concepto de razón que está usando Locke en este contexto es innecesariamente restrictiva. Con el fin de favorecer una interpretación más amplia, piénsese en la cita de Locke reportada en la página anterior que afirma que la razón es "el lazo común mediante el cual el género humano se une en camaradería y sociedad” (II, 172). 
equidad común ${ }^{21}$ - es, a su vez, una demanda de racionalidad que recae sobre todos los miembros de la sociedad política, pues, si no se considerara en esos términos el comportamiento del trasgresor, sería como si, quienes forman parte de la sociedad civil, acordaran que "todos ellos, menos uno, deben estar bajo esas leyes; y que la única persona que no está sometida a ellas retiene toda la libertad propia del estado de naturaleza (...)" (II, 93). Quienes acordaran algo como eso pueden ser llamados, según Locke, simplemente "estúpidos" (“foolish”) (II, 93).

\section{VII}

Mi propósito central ha sido mostrar cómo se podría entender el criterio de racionalidad que usa Locke al hablar de quienes trasgreden la ley natural como bestias nocivas con el fin de argumentar a favor de la compatibilidad entre dicho criterio y el principio de igualdad fundamental. Lo que he pretendido hacer es mostrar que la igualdad fundamental no se ve comprometida con la pérdida de derechos, porque esta pérdida no está basada en una manera de entender el criterio de racionalidad como base de la igualdad. No creo que la referencia de Locke a la razón como criterio de pertenencia a la comunidad natural implique hablar de sujetos que deban ser tratados como si fueran bestias salvajes porque han dejado de ser racionales en el sentido de racionalidad que los hace ser un igual para con los demás. Con el fin de esclarecer aún más el vínculo entre razón y confianza es útil señalar, nuevamente, que Locke no usa el concepto de razón de una sola manera. Lo usa, por ejemplo, como cálculo de ventajas (II, 131), como instrumento para "descubrir" el contenido de la ley natural (II, 12, 57) y como "el lazo común mediante el cual el género humano se une en camaradería y sociedad" (II, 172). Es justamente este último uso el que permite vincular la confianza con el comportamiento racional. Parece razonable pensar que el tipo de confianza necesaria para formar la sociedad civil -que, como sabemos, en Locke no es lo mismo que el gobierno- se da entre personas que puedan decirse, en un sentido amplio o inclusivo, racionales, y que cuando los individuos se comportan trasgrediendo la ley natural no están respondiendo a la confianza que hizo posible la formación de dicha sociedad. Es en este sentido, creo, en el cual debería entenderse la comparación de Locke del trasgresor con un animal nocivo o una bestia salvaje. Quien quebranta la ley natural no es digno de confianza, de manera parecida a la cual no es digno de confianza un animal nocivo. Ambos se comportan teniendo como única regla la fuerza y la violencia y, por tanto, son -en un sentido negativo- impredecibles. Parece justo castigar al trasgresor y no al animal, pues el primero, estando en posesión del punto de vista moral-i.e., el

$21 \quad$ Según Locke, quien trasgrede la ley natural está "declarando" algo: "que vive guiándose por reglas diferentes de las que manda la razón y la equidad común, las cuales son normas que Dios ha establecido para regular las acciones de los hombres en beneficio de su seguridad mutua" (II, 8). 
conocimiento de la ley natural- o pudiendo estarlo, voluntariamente daña a otro para satisfacer intereses propios y, por esa razón, ese daño representa un quiebre en las relaciones de confianza que hacen posible la vida en común.

Lo que me parece importante destacar es que, si lo que el trasgresor de la ley natural hace es quebrantar la paz y seguridad, es en relación con esos parámetros que debería entenderse la noción de razón o comportamiento racional -o, lo que es lo mismo, lo que significaría no comportarse según las normas de la recta razón. Si Locke cree que los seres humanos son iguales porque tienen la capacidad de abstracción que les permite reconocer en Dios su creador y, junto con ello, conocer su deberes morales, no se debería afirmar que la pérdida de derechos atenta contra las bases de la igualdad pues -como hemos intentado mostrar- dicha pérdida no se fundamenta en esas bases, sino que en el rompimiento de la confianza como garantía de paz y seguridad. Esto significa que, quien pierde derechos, no deja de ser un igual. Expresión de dicha igualdad es que la pérdida en cuestión es proporcional y, por tanto,--salvo en el caso de la pérdida total- momentánea. La comparación con animales debería entenderse entonces como una manera de graficar la degradación moral en la que incurre el trasgresor, sin que dicha degradación implique la pérdida de su estatus de igual.

Desde luego, la posibilidad de relacionar confianza y racionalidad para evitar que la existencia del derecho a castigar amenace el principio de igualdad, no implica creer que dicho derecho deje de ser problemático en el pensamiento de Locke. Queda por pensar, por ejemplo, el vínculo entre disuasión y confianza. Si es el rompimiento de la confianza lo que justifica que el trasgresor pierda derechos, ¿hay algo que haga que, luego de que el castigo ha sido aplicado, la confianza se restaure y, por tanto, el trasgresor vuelva a tener esos derechos? La proporcionalidad del castigo dice relación con la magnitud de la falta, pero nada hace pensar que esa proporcionalidad tenga por efecto necesario la restauración de la confianza. ¿Qué podría decir Locke en relación con este importante punto? Si es que no se encontrara una respuesta satisfactoria a esta pregunta, podrían surgir legítimas dudas respecto de la plausibilidad del vínculo propuesto en este ensayo entre pérdida de derechos y pérdida de confianza. Es posible afirmar que Locke vincula el castigo con el arrepentimiento y, podríamos agregar, es factible vincular el arrepentimiento con la restauración de la confianza. Téngase presente, por ejemplo, el siguiente pasaje: “(...) y castigar así a quien haya trasgredido esa ley haciendo de este modo que se arrepienta [repent] de haberlo hecho" (II, 8). Si hay arrepentimiento es porque, se supone, no se volverá a trasgredir la ley de naturaleza, es decir, no se volverá a romper la confianza. Por supuesto, nada garantiza que eso sea así, del mismo modo que nada garantiza que el arrepentimiento, de existir, sea efectivo y no una simple estrategia para satisfacer a quien pretende restablecer el orden. Pero este no es un problema solo para Locke, sino que para cualquier teoría que pretenda vincular castigo y arrepentimiento; un arrepentimiento, se entiende, no basado en el mero temor a ser castigado. De hecho, parece bastante natural entender el arrepentimiento como un deseo con dirección al pasado, más que como un mero temor a ser castigado nuevamente. Quien se arrepiente desea ahora no haber hecho lo que hizo, no debido a las consecuencias que se derivan del ser castigado, sino a que considera que lo que hizo estuvo mal. Independientemente de si es acertado o no llamar solo a este tipo de 
deseo "arrepentimiento", es plausible pensar que este es el único tipo de arrepentimiento capaz de restablecer la confianza. Sin embargo, no es para nada evidente si esta es efectivamente la manera en la cual Locke entiende el arrepentimiento. Esta falta de evidencia se debe, fundamentalmente, a que este no es un punto que Locke aborde con profundidad. De todas formas, las veces en que sí lo hace, su posición está más cercana al arrepentimiento como mero temor que al arrepentimiento como evaluación moral negativa de lo ya realizado ${ }^{22}$. Esto hace, por cierto, que la cuestión sea bastante problemática. Una vez que se reconoce que la confianza es un elemento central a la hora de explicar, en sus varios niveles, la vida en común, si es que el castigo no significa, en la práctica, exclusión definitiva, no debería ser entendido simplemente como una respuesta a un acto violento. A lo que se responde es, sobre todo, al quebrantamiento de la confianza y, en consecuencia, el castigo no debería buscar solo la reparación de los daños que la víctima sufre, sino también la reparación de la confianza quebrada. Si es que el castigo no apunta en esa dirección, es decir, si es que el castigo no busca alcanzar arrepentimiento moral más que prudencial y solo busca disuadir con el temor, hay razones -quizás no del todo conclusivas- para creer que nunca se recompondrá lo que alguna vez se rompió y que para Locke tiene especial importancia: la paz y la camaradería. Creo que estas razones no son del todo conclusivas, porque es posible vincular la noción de confianza con el mero arrepentimiento prudencial y mantener así la interpretación del castigo como un disuasivo basado en la severidad de la pena. Razones de carácter pragmático podrían hacer explicable por qué Locke parece creer que la severidad del castigo y la restauración de la confianza no están tan alejadas. De todas formas, es necesario señalar que esta no es una relación que Locke se haya preocupado de pensar y que, por consiguiente, lo que se diga a este respecto excede la interpretación filosófica de su pensamiento político. Me parece, de todos modos, que una interpretación lockeana de la relación entre restauración de la confianza y el castigo debería tener presente el importante y extendido papel que juega ésta ultima a la hora de explicar qué es lo que pasa -en términos morales-cuando un individuo daña a otro en sus posesiones, salud, vida y libertad.

\section{Referencias bibliográficas}

Ashcraft, Richard (1986), Revolutionary Politics and Locke's "Two Treatises of Government". Princeton: Princeton University Press.

Dunn, John (1969), The Political Thought of John Locke. An Historical Account of the Argument of the "Two Treatises of Government". Cambridge: Cambridge University Press.

22 Un ejemplo: “(...) cada trasgresión puede ser castigada en el grado y con la severidad que sea suficiente para que el ofensor salga perdiendo, para darle motivo a que se arrepienta de su acción y para atemorizar a otros con el fin de que no cometan un hecho semejante" (II, 12). 
Locke, John (1690), Two Treatises on Government, ed. Peter Laslett. Cambridge: Cambridge University Press, 1988. Traducción al español de uno de estos tratados: Segundo tratado sobre el gobierno civil. Madrid: Alianza Editorial. Traducción de Carlos Mellizo, 1990.

(1997), Essays on the Law of Nature, en Political Essays, ed. Mark Goldie. Cambridge: Cambridge University Press.

(1689), An Essay Concerning Human Understanding, ed. P. H. Nidditch. Oxford: Oxford University Press, 1971.

Quinn, Warren (1985), "The Right to Threaten and the Right to Punish", Philosophy and Public Affairs, 14, 4: 327-373.

Simmons, A. John (1992), The Lockean Theory of Rights. Princeton: Princeton University Press.

Waldron, Jeremy (2002), God, Locke, and Equality. Christian Foundations in Locke's Political Thought. Cambridge: Cambridge University Press. 